\title{
Reactive Power based Model Reference Neural Learning Adaptive System for Speed Estimation in Sensor-less Induction Motor Drives
}

\author{
K Sedhuraman*, S Himavathi and A Muthuramalingam \\ Department of Electrical and Electronics Engineering, Pondichery Engineering College, Puducherry-605014, India
}

Received 5 June 2011; accepted 5 September 2011

\begin{abstract}
In this paper, a novel reactive power based model reference neural learning adaptive system (RP-MRNLAS) is proposed. The model reference adaptive system (MRAS) based speed estimation is one of the most popular methods used for sensor-less controlled induction motor drives. In conventional MRAS, the error adaptation is done using a Proportional-integral-(PI). The non-linear mapping capability of a neural network (NN) and the powerful learning algorithms have increased the applications of NN in power electronics and drives. Thus, a neural learning algorithm is used for the adaptation mechanism in MRAS and is often referred to as a model reference neural learning adaptive system (MRNLAS). In MRNLAS, the error between the reference and neural learning adaptive models is back propagated to adjust the weights of the neural network for rotor speed estimation. The two different methods of MRNLAS are flux based (RF-MRNLAS) and reactive power based (RP-MRNLAS). The reactive power- based methods are simple and free from integral equations as compared to flux based methods. The advantage of the reactive power based method and the NN learning algorithms are exploited in this work to yield a RPMRNLAS. The performance of the proposed RP-MRNLAS is analyzed extensively. The proposed RP-MRNLAS is compared in terms of accuracy and integrator drift problems with popular rotor flux-based MRNLAS for the same system and validated through Matlab/Simulink. The superiority of the RP- MRNLAS technique is demonstrated
\end{abstract}

Keywords: Induction motor, Speed estimator, MRAS, Neural network, Back propagation algorithm, Reactive power

$$
\begin{aligned}
& \text { نوذج مرجعي معتمد على الطاقة التفاعلية لنظام تعلم عصبي متكيف لتقدير سرعة العركات التأثيرية بدون } \\
& \text { مجسات } \\
& \text { كو سوداكرنث*، س هيماوتي و أ موتوراملينغم }
\end{aligned}
$$

الملخص: يقدم هذا البحث نموذج مرجعي معتمد على الطاقة التفاعلية لنظام تعلم عصبي متكيف لتقدير سرعة المركات التأثيرية بدون مجسات

(RP-MRN-LAS)

(MRAS)

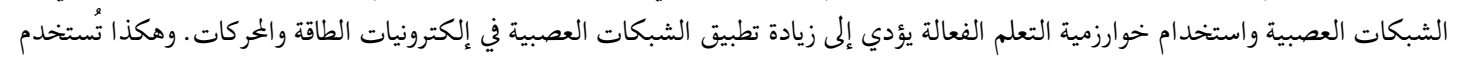

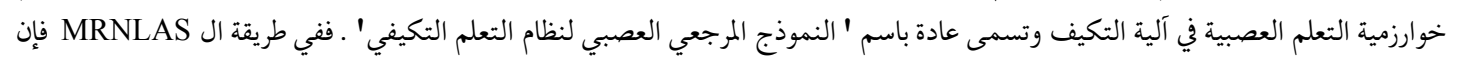

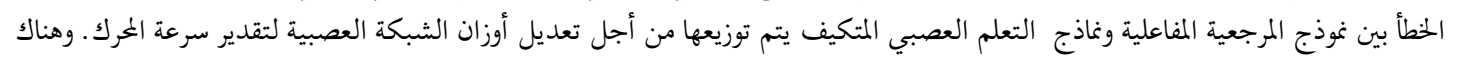

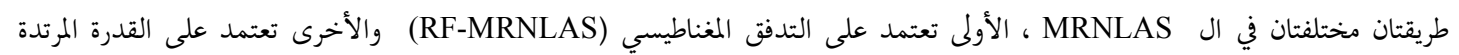

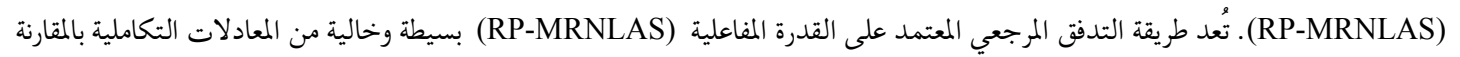

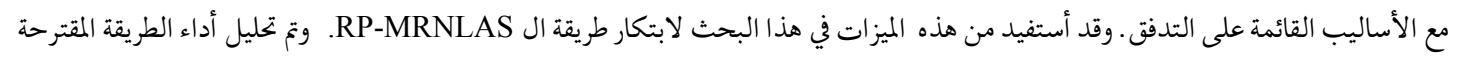

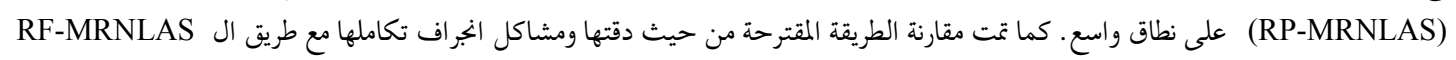

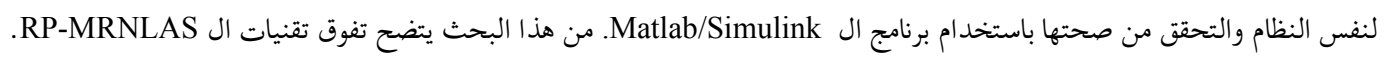

الكلمات المفتاحية: العرك التأثيري، مقدرة السرعة، النموذج المرجعي للنظام المتكيف، الشبكة العصبية، خوارزم الانتشار الخلفي، القدرة التفاعلية 


\section{Nomenclature}

$\begin{array}{lll}\mathrm{V}_{\mathrm{ds}}, \mathrm{V}_{\mathrm{qs}} & - & \mathrm{d} \text { and q components of stator voltage } \\ \mathrm{I}_{\mathrm{ds}}, \mathrm{I}_{\mathrm{qs}} & - & \mathrm{d} \text { and q components of stator current } \\ \lambda_{\mathrm{dr}}, \lambda_{\mathrm{qr}} & - & \mathrm{d} \text { and q components of rotor flux } \\ \mathrm{L}_{\mathrm{s}}, \mathrm{L}_{\mathrm{r}}, \mathrm{L}_{\mathrm{m}} & - & \text { stator, rotor and mutual inductances } \\ \mathrm{R}_{\mathrm{s}} & - & \text { resistance of stator phase winding } \\ \mathrm{R}_{\mathrm{r}} & - & \text { resistance of rotor phase winding } \\ \mathrm{T}_{\mathrm{r}} & - & \text { rotor time constant } \\ \sigma=1-\left(\mathrm{L}_{\mathrm{m}} / \mathrm{L}_{\mathrm{s}} \mathrm{L}_{\mathrm{r}}\right) & - & \text { total leakage factor } \\ \omega_{\mathrm{e}} & - & \text { stator frequency } \\ \omega_{\mathrm{sl}} & - & \text { slip frequency } \\ \omega_{\mathrm{r}} & - & \text { rotor mechanical speed } \\ \mathrm{Q} & - & \text { reactive power }\end{array}$

\section{Introduction}

Accurate knowledge of speed is essential for high performance speed control in induction motors. The speed can be measured by using mechanical sensors such as resolvers/pulse encoders. However, these sensors are usually expensive, bulky, subject to failure under hostile industrial environments, and require special attention, such as continuous maintenance and calibration. Being prone to sensor failure also increases the cost and size of the drive system. Hence, researchers have been motivated to use estimated speed instead of measured speed, and sensor-less control of induction motors has become popular.

Speed is estimated using instantaneous stator voltages and currents along with the motor model. Other approaches to estimate speed use rotor slot harmonic, extended kalman filters (EKF), the extended luenbergern observer (ELO), saliency techniques and MRAS (Bose 2002; Chen and Sheu 2002; Ferrah et al. 1997; Holts 1993; Hurst et al. 1994; Jansen and Lorenz 1996; Karanayil et al. 2007; Kubota 1994; Maiti et al. 2008; Maurizio and Marcello 2005; Mondal et al. 2002; Ohtani 1992; Peng and Fukao 1994; Rajashekara et al. 1996; Rashed and Stronach 2004; Schroedl 1996; Shauder 1992; Vas 1998; Yang and Chin 1993). MRAS schemes offer simpler implementation and require less computational efforts as compared to other methods and are, therefore, the most popular among the strategies used for sensor-less control IM drives (Chen and Sheu 2002; Karanayil et al. 2007; Kubota 1994; Maiti et al. 2008; Ohtani 1992; Peng and Fukao 1994; Shauder 1992; Yang and Chin 1993).

In a MRAS system, the outputs of two models, one independent of the rotor speed (reference model) and the other dependent (adjustable model) are used. The error vector is driven to zero by an adaptation mecha- nism (PI-controller) which yields the estimated rotor speed. Depending on the choice of output quantities that form the error vector (e.g., flux, stator current, back electro-motor force (EMF), reactive power), several MRAS structures are possible. The most common MRAS structure is that based on the rotor flux error vector (Kubota 1994; Maiti et al. 2008; Ohtani 1992; Peng and Fukao 1994; Shauder 1992; Yang and Chin 1993). The selection of reactive power as a function for a MRAS-based speed estimator deduces a simpler system model, which is easier to design and implement and become advantageous in real time applications (Maiti et al. 2008; Peng and Fukao 1994). Conventional MRAS schemes use PI controller as the adaptive mechanism for speed estimation.

Recently, the use of NNs for identification and control of nonlinear dynamic systems in power electronics and drives has been proposed as NNs they are capable of approximating wide range of nonlinear functions to any desired degree of accuracy (Chen and Sheu 2002; Karanayil et al. 2007; Lazhar et al. 1999; Mondal et al. 2002; Narendra and Parthasarathy 1990; Vas 1998). Powerful learning algorithms have been developed for neural networks (Fredric and Ivica 2008; Hagan et al. 1996).

In this paper neural learning algorithm is employed for the adaptation mechanism in MRAS instead of the PI-controller. In this MRNLAS-based speed estimation, the error between the reference model and the neural learning adaptive model is back propagated to adjust the weights of the neural learning adaptive model to estimate the speed of an induction motor drive. A number of learning algorithms are available for supervised learning in the NN. As this application requires on-line learning, back propagation with the 


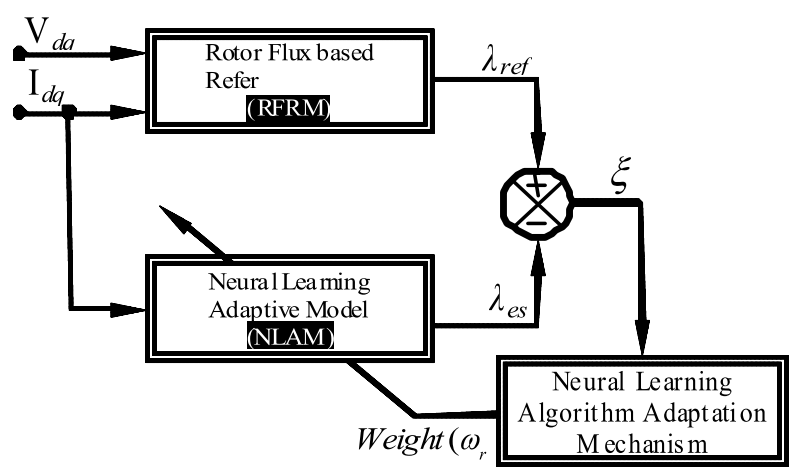

Figure 1. Speed estimation using flux based MRNLAS (RF-MRNLAS)

momentum algorithm is chosen as it the simplest algorithm with minimum time for convergence.

The learning algorithm is based on the powerful steepest descent method (Fredric and Ivica 2001; Hagan et al. 1996). In this method, the weights of NN are adjusted in steps to minimize the performance index: mean squared error. The learning rate employed in the algorithm determines the step size. Greater learning rates mean faster learning within the of $\mathrm{NN}$, but, this can lead to oscillations in the output and result in a missed global minimum point. To overcome this difficulty and reduce oscillations in the output, a momentum term is added to smooth the oscillations and accelerate the convergence.

Hence, in this paper a novel RP-MRNLAS is proposed. Its speed estimation is compared with the popular RF-MRNLAS to identify the most suitable speed estimation method for speed sensor-less induction motor drives.

Section 2 briefly outlines the proposed RP-MRNLAS-based speed estimator utilizing reactive power equations for both the reference model and the neural learning adaptive model and popular RF-MRNLAS. Section 3 describes the closed loop operation of spee sensor-less-vector controlled induction motor drives. Section 4 details the simulation results obtained for the proposed RP-MRNLAS based speed estimator. Section 5 compares the proposed RP-MRNLAS with the popular RF-MRNLAS. Section 6 concludes the paper.

\section{MRNLAS-Based Estimator}

\subsection{The RF-MRNLAS Structure}

The speed of an induction motor can be estimated using the neural learning algorithm-based MRAS system as illustrated in Figure 1. In this method of speed estimation, the rotor fluxes of the induction motor are selected to represent the actual and estimated state variables. Two independent observers are used to esti- mate the rotor flux of the induction motor. Equation 1 is based on stator voltages and currents and is called as voltage model equation and (reference model) is independent of speed, and Eqn. (2) is based on stator currents and rotor speed, and is called a current model equation. The current model equations are classified as a neural learning adaptive model (Karanayil et al. 2007; Ben-Hrahim et al. 1999; Vas 1998). The neural learning algorithm is used as an adaptive mechanism for rotor speed estimation.

The flux estimations which use voltage model equations are used as the reference value, and the flux estimation using a neural representation of current model equations are used as estimated values. The difference between these stated variables is then used by the neural learning mechanism (adaptation mechanism) to track the actual speed. The learning continues until the performance index is met.

Voltage Model

$\left[\begin{array}{c}\frac{\mathrm{d} \lambda_{\mathrm{dr}}}{\mathrm{dt}} \\ \frac{\mathrm{d} \lambda_{\mathrm{qr}}}{\mathrm{dt}}\end{array}\right]=\frac{\mathrm{L}_{\mathrm{r}}}{\mathrm{L}_{\mathrm{m}}}\left[\left[\begin{array}{c}\mathrm{V}_{\mathrm{ds}} \\ \mathrm{V}_{\mathrm{qs}}\end{array}\right]-\left[\begin{array}{cc}\mathrm{R}_{\mathrm{s}}+\mathrm{s} \sigma \mathrm{L}_{\mathrm{s}} & 0 \\ 0 & \mathrm{R}_{\mathrm{s}}+\mathrm{s} \sigma \mathrm{L}_{\mathrm{s}}\end{array}\right]\left[\begin{array}{c}\mathrm{I}_{\mathrm{ds}} \\ \mathrm{I}_{\mathrm{qs}}\end{array}\right]\right](1)$

Current Model

$\left[\begin{array}{c}\frac{\mathrm{d} \lambda_{\mathrm{dr}}}{\mathrm{dt}} \\ \frac{\mathrm{d} \lambda_{\mathrm{qr}}}{\mathrm{dt}}\end{array}\right]=\left[\begin{array}{cc}\frac{-1}{\mathrm{~T}_{\mathrm{r}}} & -\omega_{\mathrm{r}} \\ \omega_{\mathrm{r}} & \frac{-1}{\mathrm{~T}_{\mathrm{r}}}\end{array}\right]\left[\begin{array}{l}\lambda_{\mathrm{dr}} \\ \lambda_{\mathrm{qr}}\end{array}\right]+\frac{\mathrm{L}_{\mathrm{m}}}{\mathrm{T}_{\mathrm{r}}}\left[\begin{array}{l}\mathrm{I}_{\mathrm{ds}} \\ \mathrm{I}_{\mathrm{qs}}\end{array}\right]$

The Eqn. (2) is rewritten in neural network formand is given in Eqns. $(3,4)$.

$\lambda_{\mathrm{dr}}^{\mathrm{nm}}(k)=W_{1} \lambda_{\mathrm{dr}}^{\mathrm{nm}}(k-1)-W_{2} \lambda_{\mathrm{qr}}^{\mathrm{nm}}(k-1)+W_{3} \mathrm{I}_{\mathrm{ds}}(k-1)$ 


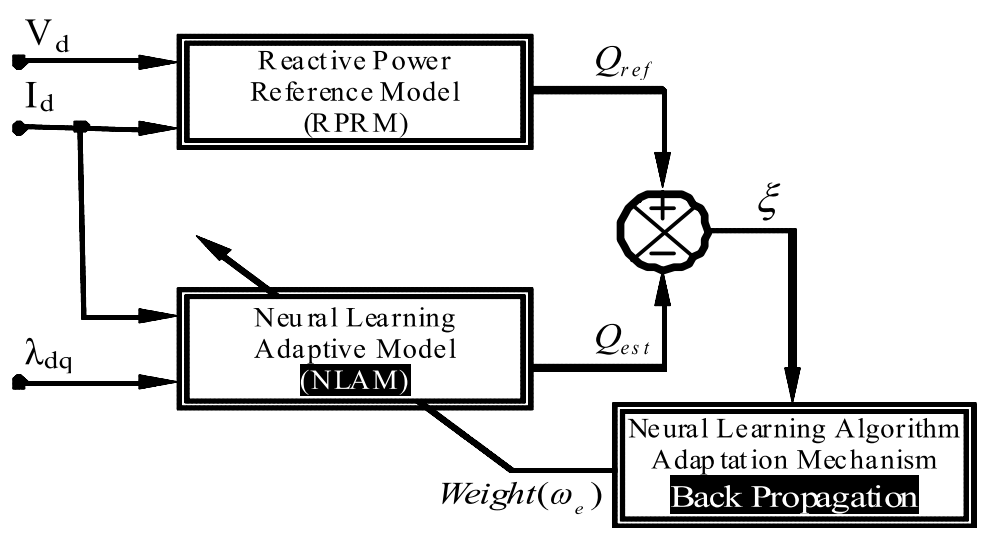

Figure 2. Speed estimation using reactive power based MIRLAS (RP-MRNLAS)

$$
\lambda_{\mathrm{qr}}^{\mathrm{nm}}(k)=W_{l} \lambda_{\mathrm{qr}}^{\mathrm{nm}}(k-1)+W_{2} \lambda_{\mathrm{dr}}^{\mathrm{nm}}(k-1)+W_{3} \mathrm{I}_{\mathrm{qs}}(k-1)
$$

where,

$W_{1}=1-\left(\mathrm{T}_{\mathrm{s}} / \mathrm{T}_{\mathrm{r}}\right), W_{2}=\omega_{\mathrm{r}} \mathrm{T}_{\mathrm{s}}$ and $W_{3}=\left(\mathrm{L}_{\mathrm{m}} \mathrm{T}_{\mathrm{s}}\right) / \mathrm{T}_{\mathrm{r}}$

$\mathrm{T}_{s}$ is the sampling time.

The updated equations for the rotor speed estimation of RF-MRNLAS are given in (Karanayil et al. 2007; Ben-Brahim et al. 1999; Vas 1998). The RFMRNLAS schemes require pure integrators in the reference models since it is the voltage model of an induction motor. The selection of an reactive power as a function for the MRNLAS (RP-MRNLAS) based speed estimator deduces a simpler system model, which is easier to design and implement and becomes advantageous in real time applications (Maiti et al. 2008; Peng and Fukao 1994). Also, the reference model obtained using reactive power is independent of the pure integrator.

\subsection{Proposed Reactive Power based MRNLAS Structure (RP-MRNLAS)}

The stated variable used is the reactive power. The reference model and neural learning adaptive model compute instantaneous reactive power $\left(Q_{\text {ref }}\right)$ and steady-state reactive power $\left(Q_{e s t}\right)$ respectively. The reference model is independent of $\omega_{e}$ whereas the adjustable model depends on $\omega_{e}$. The error signal $(\xi=$ $\left.Q_{r e f}-Q_{e s t}\right)$ is back propagated to adjust the weight $\left(\omega_{e}\right.$ $=$ Weight $)$ of the neural learning adaptive model. The rotor speed $\left(\omega_{r}\right)$ is then computed using $\omega_{r}=\omega_{e}-\omega_{s l}$, where, $\omega_{e}$ is the stator frequency and $\omega_{s 1}$ is the slip frequency.

The block diagram of the proposed reactive power based MRNLAS (RP-MRNLAS) system for rotor/motor speed estimation is illustrated in Figure 2. The equations defining the induction motor reference model and adjustable model based on reactive power are given below.

The $\mathrm{d}$ and $\mathrm{q}$ axis stator voltages of an induction motor can be expressed on a synchronously rotating reference frame as given in (5) and (6).

$$
\begin{aligned}
& \mathrm{V}_{\mathrm{ds}}=\mathrm{R}_{\mathrm{s}} \mathrm{I}_{\mathrm{ds}}+\sigma \mathrm{L}_{\mathrm{s}} \frac{\mathrm{d}}{\mathrm{dt}} \mathrm{I}_{\mathrm{ds}}+\frac{\mathrm{L}_{\mathrm{m}}}{\mathrm{L}_{\mathrm{r}}} \frac{\mathrm{d}}{\mathrm{dt}} \lambda_{\mathrm{dr}}-\sigma \mathrm{L}_{\mathrm{s}} \omega_{\mathrm{e}} \mathrm{I}_{\mathrm{qs}}-\omega_{\mathrm{e}} \frac{\mathrm{L}_{\mathrm{m}}}{\mathrm{L}_{\mathrm{r}}} \lambda_{\mathrm{qr}} \\
& \mathrm{V}_{\mathrm{qs}}=\mathrm{R}_{\mathrm{s}} \mathrm{I}_{\mathrm{qs}}+\sigma \mathrm{L}_{\mathrm{s}} \frac{\mathrm{d}}{\mathrm{dt}} \mathrm{I}_{\mathrm{qs}}+\frac{\mathrm{L}_{\mathrm{m}}}{\mathrm{L}_{\mathrm{r}}} \frac{\mathrm{d}}{\mathrm{dt}} \lambda_{\mathrm{qr}}+\sigma \mathrm{L}_{\mathrm{s}} \omega_{\mathrm{e}} \mathrm{I}_{\mathrm{ds}}+\omega_{\mathrm{e}} \frac{\mathrm{L}_{\mathrm{m}}}{\mathrm{L}_{\mathrm{r}}} \lambda_{\mathrm{dr}}
\end{aligned}
$$

The actual instantaneous reactive power $\left(Q_{\text {ref }}\right)$ absorbed by the induction motor can be expressed as in (7). Using the flux and parameter of the induction motor, the estimated reactive power $\left(Q_{e s t}\right)$ can be expressed as Eqns. $(8,9)$. Rewriting Eqn. (9) in the form of neural network, it is given in Eqn. (10).

$$
\begin{aligned}
& Q_{r e f}=\mathrm{V}_{\mathrm{qs}} \mathrm{I}_{\mathrm{ds}}-\mathrm{V}_{\mathrm{ds}} \mathrm{I}_{\mathrm{qs}} \\
& Q_{e s t}=\omega_{\mathrm{e}} \sigma \mathrm{L}_{\mathrm{s}}\left(\mathrm{I}_{\mathrm{ds}}^{2}+\mathrm{I}_{\mathrm{qs}}^{2}\right)+\omega_{\mathrm{e}} \frac{\mathrm{L}_{\mathrm{m}}}{\mathrm{L}_{\mathrm{r}}}\left(\lambda_{\mathrm{qs}} \mathrm{I}_{\mathrm{qs}}+\lambda_{\mathrm{ds}} \mathrm{I}_{\mathrm{ds}}\right) \\
& Q_{\text {sst }}=\omega_{\mathrm{e}}\left(\sigma \mathrm{L}_{\mathrm{s}}\left(\mathrm{I}_{\mathrm{ds}}^{2}+\mathrm{I}_{\mathrm{q}}^{2}\right)+\frac{\mathrm{L}_{\mathrm{m}}}{\mathrm{L}_{\mathrm{r}}}\left(\lambda_{\mathrm{q}} \mathrm{I}_{\mathrm{q}}+\lambda_{\mathrm{ds}} \mathrm{I}_{\mathrm{ds}}\right)\right) \\
& Q_{e s t}=W_{l} \times P
\end{aligned}
$$

where

$$
W_{I}=\omega_{e} \text { and } P=\sigma \mathrm{L}_{\mathrm{s}}\left(\mathrm{I}_{\mathrm{ds}}^{2}+\mathrm{I}_{\mathrm{qs}}^{2}\right)+\frac{\mathrm{L}_{\mathrm{m}}}{\mathrm{L}_{\mathrm{r}}}\left(\lambda_{\mathrm{qs}} \mathrm{I}_{\mathrm{qs}}+\lambda_{\mathrm{ds}} \mathrm{I}_{\mathrm{ds}}\right)
$$

The neural learning algorithm is obtained for the model represented by Eqn. (10), where $W_{l}$ represents the weight of the network and $P$ is a function of currents, flux and parameter of the induction motor. Hence, the inputs to the neural learning adaptive model are current and flux as shown in Figure 2. The 
energy function $\mathrm{E}$ minimizes the difference between actual and estimated reactive power and is given in Eqn. (11). The back-propagation learning rule with momentum is used to minimize the energy function. For the neural learning adaptive model, the change in weight is given in Eqn. (12). Appropriate choice of learning rate $(\alpha)$ and momentum $(\eta)$ will yield the best result. The weight update equations are given in Eqn. (13). The estimated stator frequency $\left(\omega_{e}\right)$ can be calculated from $W_{l}$ and rotor speed $\omega_{r}$ ) and is obtained using the relation $\omega_{r}=\omega_{e}-\omega_{s 1}$.

$$
\begin{aligned}
& E=\frac{1}{2}\left(Q_{r e f}-Q_{e s t}\right)^{2} \\
& \Delta W_{1}(k)=\alpha[E \times P] \\
& W_{1}(k)=W_{1}(k-1)+\Delta W_{1}(k)+\eta \Delta W_{1}(k-1)
\end{aligned}
$$

\section{Speed-Sensorless Vector Controlled IM Drives}

The speed-sensorless vector control presented here is indirect field oriented control (rotor flux oriented control). Figure 2 shows the overall block diagram of the speed-sensorless drive system of an induction motor using an MRNLAS speed estimator. The system consists of a solid state IM drive system, rotor flux oriented control, and MRNLAS speed estimator. MRNLAS speed estimator as explained in section 2. Rotor flux oriented control consists of a PI speed controller, a current acontroller, and a pulse width modulation (PWM) generator.

The torque command is generated as a function of the speed error signal, and is generally processed through a PI controller. The torque and flux command are processed in the calculation block. The three phase reference current generated from the functional block is compared with the actual current in the hysteresis band's current controller and the controller takes the necessary action to produce PWM pulses. The PWM pulses are used to trigger the current source inverter to drive the induction motor.

\section{Simulation Results and Discussion of Proposed RP-MRNLAS}

The performance of the proposed RP-MRNLAS based rotor speed estimator utilizing the reactive power method for induction motor is experimented and analyzed extensively under various operating conditions. The Matlab/Simulink block diagram is shown in Figure 5. The sample results for the proposed model are shown for the following operating conditions as listed below:

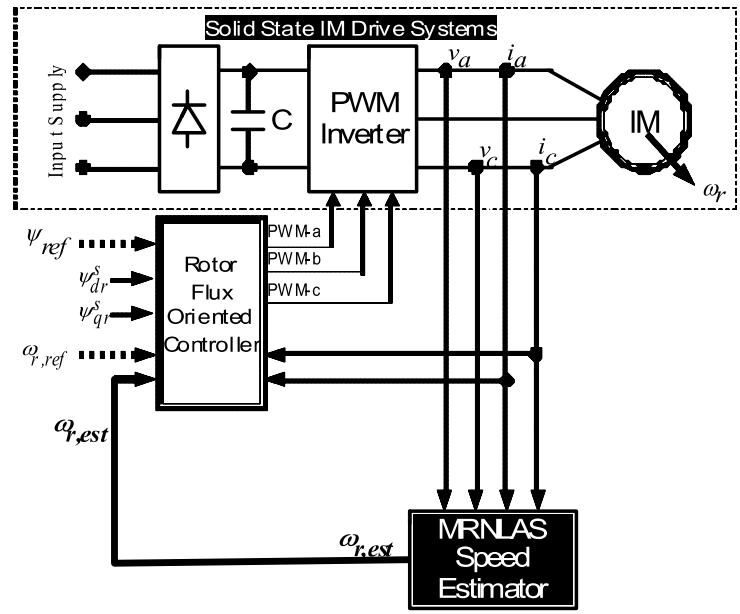

Figure 3. Sensor-less vector controlled IM drives with MRNLAS speed estimators

1. Rated speed at no load

2. Rated speed at full load

3. Rated speed at change of load

a) Ramp load

b) Step load

4. Step change in speed
(i) No load
(ii) Full load

5. Low speed at no load

The performance of the speed estimator for operating condition 1 is as shown in Figure 5. Both the actual and estimated speeds are shown when the motor operates at the rated speed under the no load condition. The estimator is tested under the loaded condition and the speed estimated is recorded for the operating condition-2 and presented in Figure 6. The estimated speed tracks the actual speed very well in both transient and steady states and settles down to yield a speed that is similar to the actual speed in both conditions. The speed estimator performance for ramp load changes is presented in Figure 7. The motor at no-load is loaded and unloaded gradually from 1.5 to $2.5 \mathrm{sec}-$ onds. The speed estimator performance for step load changes is presented in Figure 8. The motor, when running at the rated speed of no load has at 1.5 seconds, a step change in load (100\%), and step load (100\%) is rejected at 2.5 seconds. The speed estimation for operating condition 4 is shown in Figures 9 and 10. The speed of the motor is made to change from 100 to $50 \%$ at 2 seconds, and from 50 to $100 \%$ in 4 seconds under the, no load condition in Figure 9. The motor speed is made to change from 100 to $50 \%$ at 2 seconds and 50 to $100 \%$ in 4 seconds under the rated load condition as shown in Figure 10. The speed estimation for the low speed condition is shown in Figure 11. The speed of the motor is made to run at a low speed of 3.8 radi- 


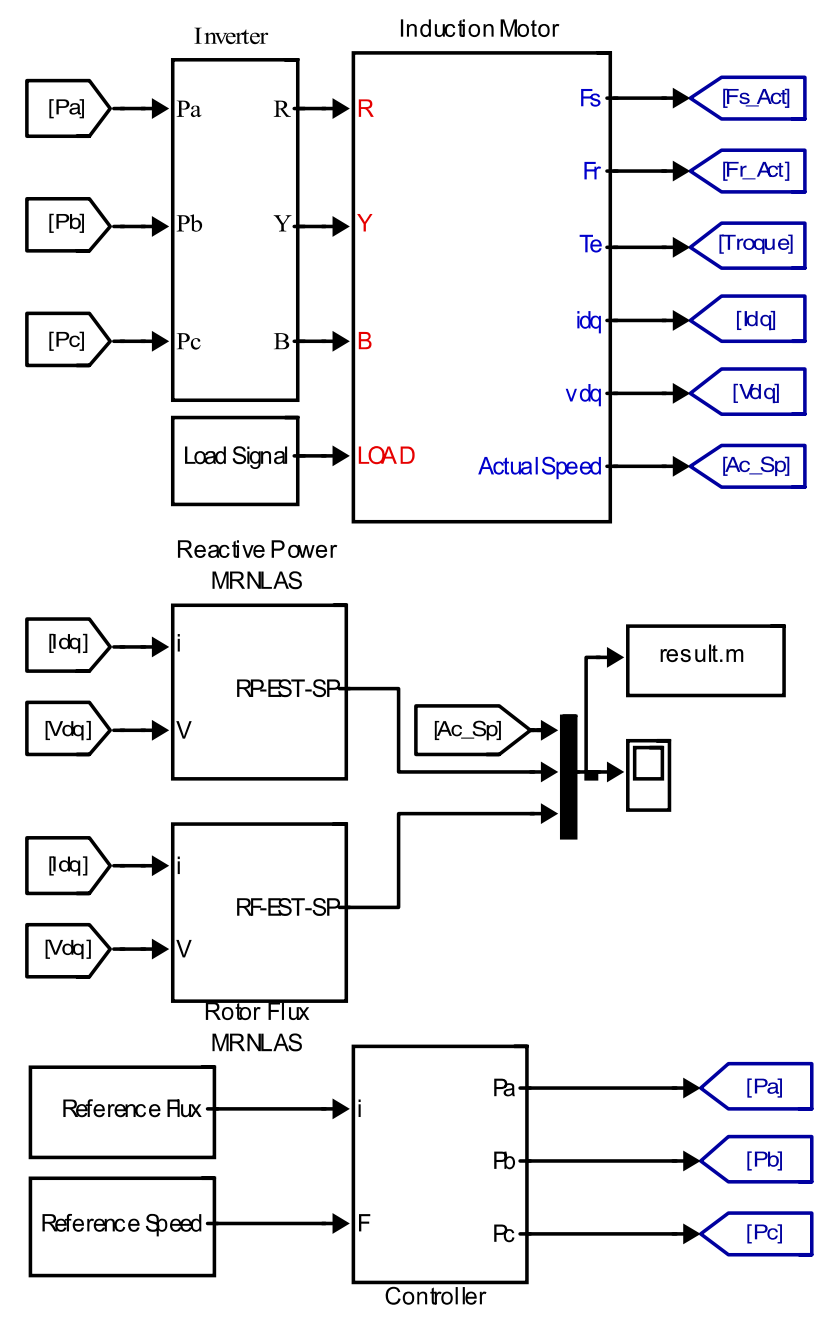

Figure 4. Matlab/simulink block diagram of sensorless controlled IM drives with MRNLAS speed estimates

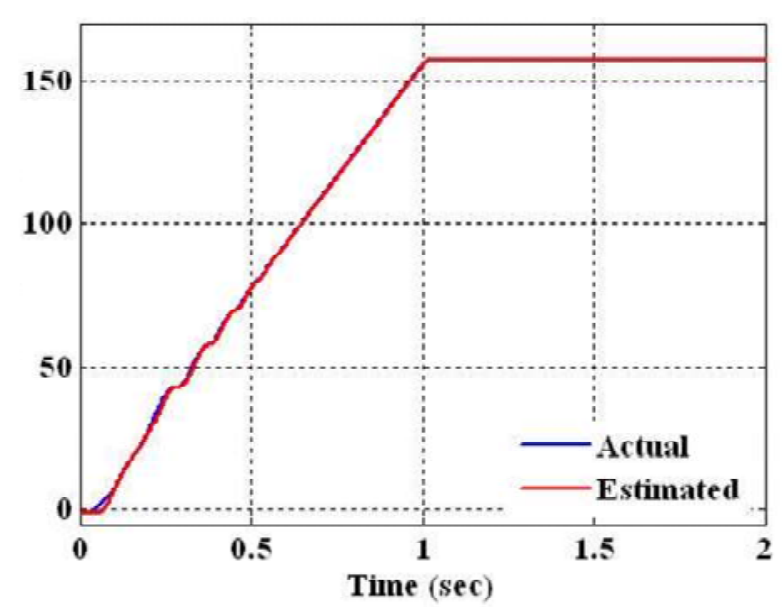

Figure 5. Actual and estimated rotor speed during starting with no load

ans/second under the no load condition.

The steady state and transient performance of the

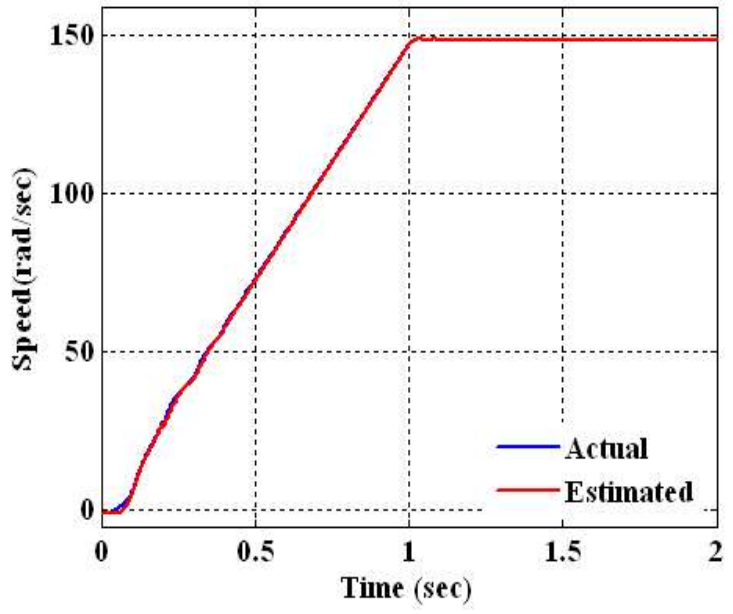

Figure 6. Actual and estimated rotor speed during starting with full load

proposed RP-MRNLAS for speed estimation under various operating conditions are studied extensively. 


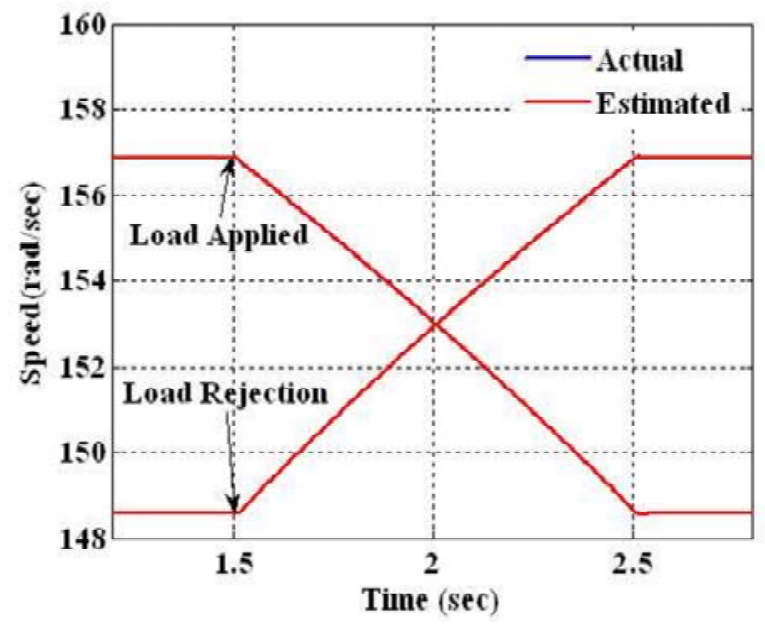

Figure 7. Actual and estimated rotor speed for ramp change in load

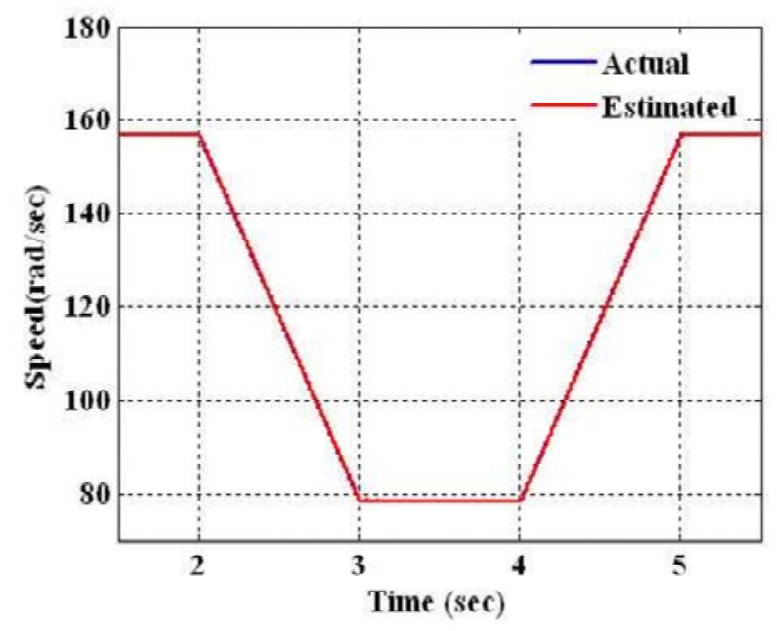

Figure 9. Actual and estimated rotor speed for change in speed (100\% to $50 \%)$ at no load

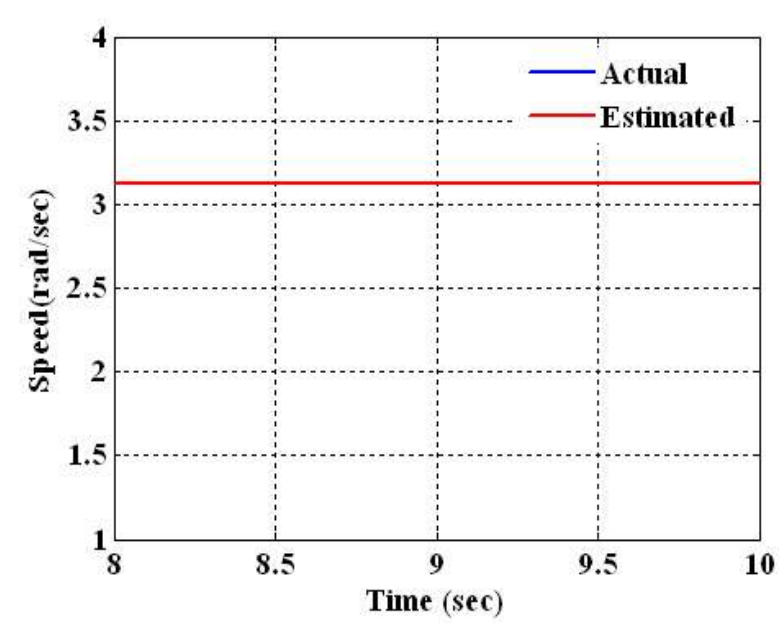

Figure 11. Actual and estimated rotor speed at low speed condition

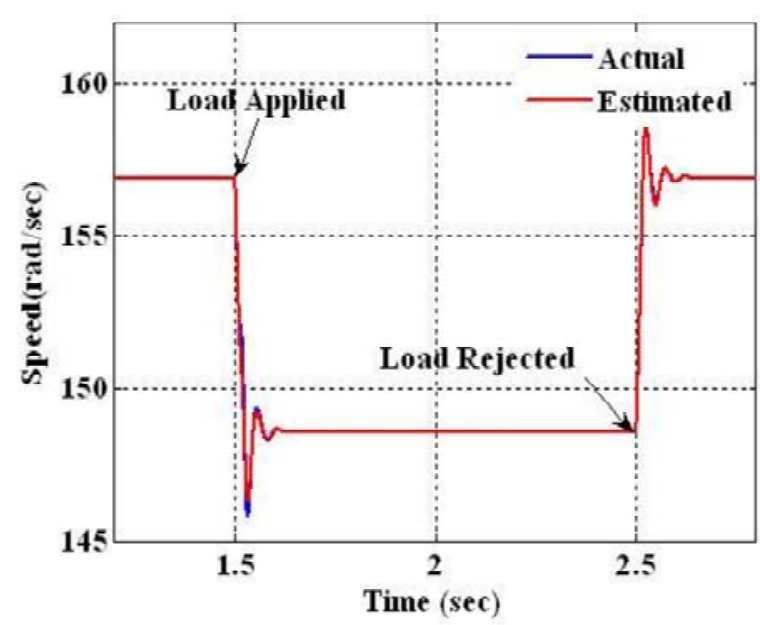

Figure 8. Actual and estimated rotor speed for step change in load

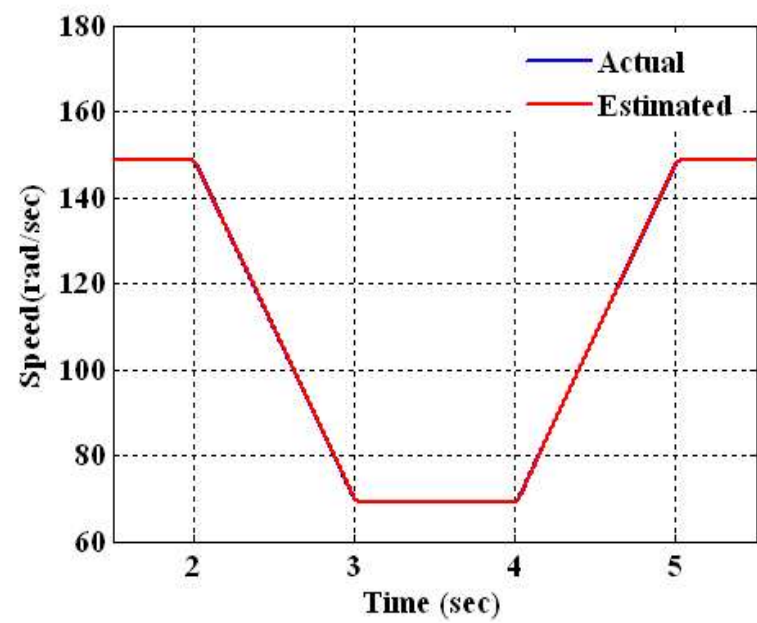

Figure 10. Actual and estimated rotor speed for change in speed $(100 \%$ to $50 \%)$ at full load

From the results obtained, the proposed model estimated speed very well for all operating conditions, and settled to a speed similar to actual speed.

\section{Performance Comparison of RP-MRN- LAS and RF-MRNLAS}

The comparisons of RP-MRNLAS and RF-MRNLAS for speed estimation at an steady state were carried out and the results obtained are consolidated and presented in Table 1.

Both MRNLAS-based speed estimator have been shown to track the actual speed over a wide range of $1.8 \mathrm{rad} / \mathrm{sec}$ to $156.8 \mathrm{radians} / \mathrm{seconds}$ in Table I. From the results obtained, RF-MRNLAS estimated rotor speed tracks the actual rotor speed with an accuracy of $0.02 \%$ for a normal operating speed range and a maximum of $0.69 \%$ at low and very low speeds. The 
K Sedhuraman, S Himavathi and A Muthuramalingam

Table 1. Steady state performance comparison of MRNLAS based speed estimators

\begin{tabular}{rrrrrr}
\hline \hline \multirow{2}{*}{$\begin{array}{l}\text { Voltage } \\
\text { (Volt) }\end{array}$} & $\begin{array}{c}\text { Actual } \\
\text { Speed } \\
(\mathrm{rad} / \mathrm{sec})\end{array}$ & $\begin{array}{c}\text { Rstimated } \\
\text { Speed } \\
(\mathrm{rad} / \mathrm{sec})\end{array}$ & $\begin{array}{c}\text { \% Error } \\
(\mathrm{rad} / \mathrm{sec})\end{array}$ & $\begin{array}{c}\text { Estimated } \\
\text { Speed } \\
(\mathrm{rad} / \mathrm{sec})\end{array}$ & $\begin{array}{c}\text { \% Error } \\
(\mathrm{rad} / \mathrm{sec})\end{array}$ \\
\hline 415 & 156.872 & 156.907 & 0.022 & 156.871 & 0.0006 \\
400 & 151.198 & 151.245 & 0.031 & 151.196 & 0.0013 \\
300 & 113.399 & 113.417 & 0.015 & 113.397 & 0.0017 \\
200 & 75.599 & 75.544 & 0.072 & 75.591 & 0.0105 \\
100 & 37.799 & 37.791 & 0.021 & 37.792 & 0.0185 \\
50 & 18.897 & 18.896 & 0.005 & 18.896 & 0.0052 \\
10 & 3.768 & 3.759 & 0.238 & 3.767 & 0.0265 \\
5 & 1.866 & 1.853 & 0.696 & 1.865 & 0.0535 \\
\hline
\end{tabular}

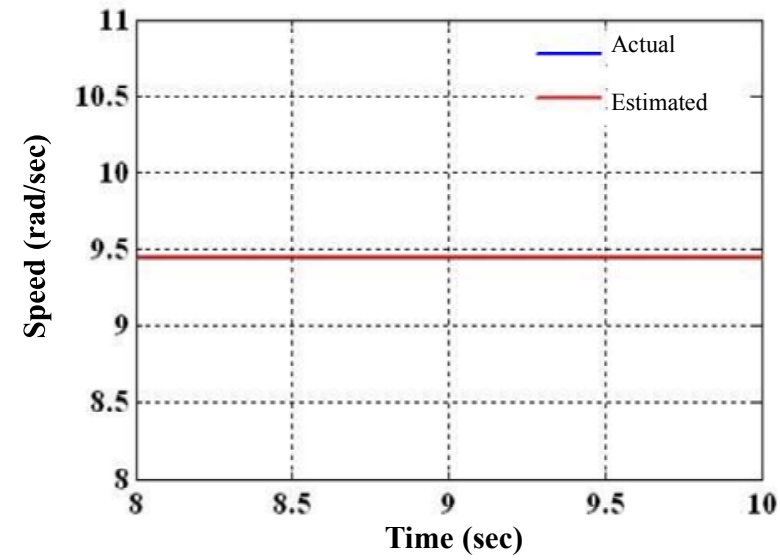

(a)

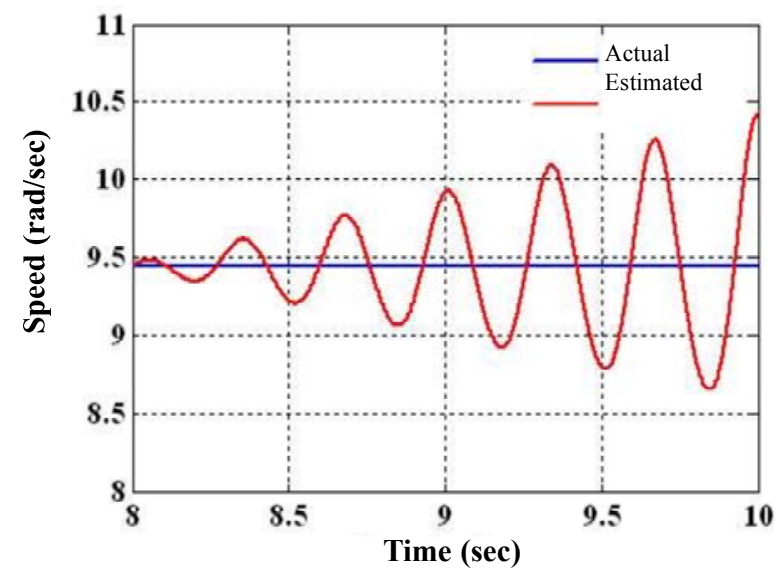

(b)

Figure 12. Response of MRNLAS based speed estimator for integrator drift problem: (a) RP-MRNLAS (b) RF-MRNLAS

proposed RP-MRNLAS estimates the speed with an accuracy of $0.01 \%$ for a normal operating speed range and a maximum value of $0.05 \%$ at low and very low speeds. The result presented for both estimators is a 0.2 meters/second sampling time to track the speed for the stated accuracy. From Table I, it is clear that the proposed RP-MRNLAS model has better accuracy than RF-MRNLAS but, for implementation, a less complex model is required. The RP-MRNLAS is simpler and easier to implement as low-cost digital hardware.

The performance of RP-MRNLAS and RF-MRNLAS are also investigated for integrator drift problems. A dc bias in the measured signal for integration is inevitable, no matter how small it is, and makes the estimated speed drift vary from the actual. The drift problem was investigated under a very low speed of 9.4 radians/second at a no load condition. A de bias of $2 \%$ is added to the input of the reference model of RPMRNLAS and RF-MRNLAS.

The performance of RP-MRNLAS and RF-MRNLAS for the dc drift problem is presented in Figures 12(a) and 12(b). For the comparison, both the figures are shown at the same scale. From the results obtained, it is seen that the RP-MRNLAS based speed estimation displays stable performance tracks at actual speed well, whereas RF-MRNLAS becomes unstable and fails to estimate. Thus, the RP-MRNLAS-based speed estimator is found to be less sensitive to the dc bias problem. This is due to the inherent absence of an integrator in the reference model of the RP-MRNLAS, where as rotor speed estimated from the RF-MRNLAS gets deviated from the actual speed due to the presence of the integrator in the reference model (voltage model). It is also noted that the error in the rotor speed keeps on increasing with time. Thus, from the above analysis, it is understood that RP-MRNLAS exhibits stable performance where as RF-MRNLAS shows unstable performance with the presence of a small dc bias. The proposed RP-MRNLAS-based speed estimator is accurate, less complex, and free from integrator drift problems, so it is a promising alternative to RFMRNLAS with speed estimators and sensor-less, vector controlled IM drives.

\section{Conclusions}

This paper proposes a novel reactive power-based 
MRNLAS (RP-MRNLAS) for speed estimation. The choice of reactive power as a functional candidate in RP-MRNLAS based speed estimation makes the system model equations simpler and easier to design. The proposed method is compared with existing rotor flux MRNLAS (RF-MRNLAS). Both the flux-based and reactive power-based MRNLAS speed estimators work very well under all operating condition (1.8 radians/second to 156.8 radians/second). The maximum percentage of speed error between the actual and estimated speed for the proposed RP-MRNLAS is found to be less than $0.05 \%$, where as the RF-MRNLAS has a maximum error of $0.69 \%$. Hence, it can be concluded that the proposed reactive power-based MRNLAS (RP-MRNLAS) is superior in terms of accuracy.

The integrator drift problem of RP-MRNLAS and RF-MRNLAS are analyzed and the results obtained are presented. The RF-MRNLAS requires pure a integrator in the reference model, where as the RP-MRNLAS-based model is completely independent of integration problems. Hence, RP-MRNLAS outperforms the RF-MRNLAS at low speeds.

The RP-MRNLAS-based speed estimator utilizes reactive power and neural learning adaptations is shown to exhibit good performance over a wide operating range with improved accuracy. The proposed RP-MRNLAS-based speed estimator, which is accurate, less complex and resistent to integrator drift problems is a more promising alternative than the RFMRNLAS-based speed estimators for sensor-less, vector-controlled IM drives.

\section{Acknowledgment}

The research project entitled "AI Techniques for Electrical Drives" was supported by grants from the All India Council for Technical Education (AICTE) which is a statutory body of the Government of India. File Number: No 8023/BOR/RID/RPS-79/2007-08 and 8020/ RID/ TAPTEC-32 /2001-02).

\section{References}

Bose BK (2001), Modern power electronics and AC drives. Prentice Hall of India.

Ben-Brahim L, Tadakuma S, Akdag, A (1999), Speed control of induction motor without rotational transducers. IEEE Trans. on Industry Applications 35(4):844-850.

Chen T, Sheu T (2002), Model reference neural network controller for induction motor speed control. IEEE Trans. on Energy Conversion 17(2).

Ferrah A, Hogben-Laing P, Bradley K, Asher G, Woolfson M (1997), The effect of rotor design on sensorless speed estimation using rotor slot harmonics by adaptive digital filtering using the max- imum likelihood approach. In Conference Proceedings of the IEEE IAS Annual Meeting 128-135.

Fredric MH, Ivica K (2001), Principles of neurocomputing for Science and Engineering. Tata McGraw-Hill Pvt. Ltd, India.

Hagan MT, Demuth HB, Baela M (1996), Neural network design. Cengage Learning, Pvt. Ltd. India.

Holts J (1993), Methods for speed sensorless control of AC drives. IEEE PCC, Yokohama 415-420.

Hurst K, Habetler T, Griva G, Profumo F (1994), Speed sensorless field-oriented control of induction machines using current harmonic spectral estimation. In Conference Record of Industry Applications Society Annual Meeting, IEEE 1: 601-607.

Jansen PL, Lorenz RD (1996), Transducer less field orientation concepts employing saturationinduced saliencies in induction machines. IEEE Trans. on Industry Applications 32:1380-1393.

Karanayil M, Rahman MF, Grantham C (2007), Online stator and rotor resistance estimation scheme using artificial neural networks for vector controlled speed sensorless induction motor drive. IEEE Trans. on Industrial Electronics 54(1).

Kubota H (1994), Speed sensorless field-oriented control of induction motor with rotor resistance adaptation. IEEE Trans. on Industry Applications 30(5):414-418.

Maiti S, Chakraborty C, Hori Y, Ta MC (2008), Model reference adaptive controller-based rotor resistance and speed estimation techniques for vector controlled induction motor drive utilizing reactive power. IEEE Trans. on Industry Electronics 55(2):594-601.

Maurizio C, Marcello P (2005), An MRAS-Based sensorless high-performance induction motor drive with a predictive adaptive model. IEEE Trans. on Industrial Electronics 52:532-551.

Mondal SK, Pinto JOP, Bose BK (2002), A neural network based space vector PWM controller for a three voltage fed inviter induction motor drive. IEEE Trans. on Industry Applications 30(3):660669.

Narendra K, Parthasarathy K (1990), Identification and control of dynamical system using neural network. IEEE Trans. on Neural Networks 1(1):4-27.

Ohtani T (1992), "Vector control of induction motor without shaft encoder. IEEE Trans. on Industry Applications 28(1):157-164.

Peng FZ, Fukao T (1994), Robust speed identification for speed sensorless vector control of induction machines. IEEE Trans. on Industry Applications IA-30(5): 1234-1230.

Rajashekara K, Kawamura A, Matsue K (1996), Sensorless control of AC motor drives. IEEE Press. 


\section{K Sedhuraman, S Himavathi and A Muthuramalingam}

Rashed M, Stronach AF (2004), A stable back-EMF MRAS-based sensorless low speed induction motor drive insensitive to stator resistance variation. Proc. Inst. Elect. Eng.-Electr. Power Appl, 151(6):685-693.

Schroedl M (1996), Sensorless control of ac machines at low speed and standstill based on the "inform" method. in Conference Record of the $31^{\text {st }}$ Annual Meeting of the IAS, IEEE 1:270-277.

Shauder C (1992), Adaptive speed identification for vector control of induction motors without rotational transducers. IEEE Trans. on Industry Applications 28(5):1054-1061.

Vas P (1998), Sensorless vector and direct torque control. Oxford Science Publication.

Yang G, Chin T (1993), Adaptive-speed identification scheme for a vector-controlled speed sensorless inverter-induction motor drive. IEEE Trans. on Industry Applications 29(4):820-825. 